\title{
Peripheral Neurophathies Associated With Chronic Renal Failure
}

\author{
C.F. BOLTON
}

\begin{abstract}
SUMMARY: $A$ variety of peripheral nerve disorders may be associated with chronic renal failure. The polyneuropathy due to uremic toxins is a distal, motor and sensory polyneuropathy in which there is segmental demyelination, axonal degeneration, and segmental remyelination. The nature of the uremic toxin and the underlying mechanism of these changes is unknown.

The incidence in patients with "endstage" renal disease has fallen in recent
\end{abstract}

RESUME: L'insuffisance rénale chronique peut s'accompagner d'une variété de troubles nerveux périphériques. La polyneuropathie toxique de l'urémie est distale, mixte (sensitivo-motrice) et se caractérise par une démyélinisation segmentaire, une dégénérescence axonale et une remyélinisation segmentaire. Nous ne connaissons pas encore la nature de la toxine urémique ou de ses mécanismes d'action.

Lincidence de ces polyneuropathies chez les patients terminaux avec urémie a nettement diminué au cours des dernières years, severe cases now being rare, perhaps due to refinements in chronic hemodialy. sis, transplantation, and other therapies. However, while chronic hemodialysis stabilizes uremic neuropathy, manipulation of hemodialysis schedules may not alter its course, according to current assessment. Successful renal transplantation improves both the clinical and electrophysiological signs, even in severe uremic neuropathy.

années, surtout en ce qui concerne les cas sévères. Ceci est probablement dû aux rafinements de l'hémodialyse chronique, des transplantations, et des autres approches thérapeutiques. S'il est vrai que l'hémodialyse chronique stabilise la neuropathie urémique, il est impossible d'en altérer la cédule pour modifier l'évolution du processus. Une transplantation rénale faite avec succès améliore et l'état clinique et les signes électrophysiologiques, même dans la neuropathie urémique sévère.
From the Department of Clinical Neurological Sciences, Victoria Hospital, University of Western Ontario, London, and the Department of Medicine, University Hospital, University of Saskatchewan, Saskatoon, Canada.

Reprint requests to: Dr. C. F. Bolton, Department of Clinical Neurological Sciences, Victoria Hospital, South Street Campus, London, Ontario, Canada, N6A 4G5, Canada.
"The third group is composed of cases in which the weakness of the limbs, observed in the course of urinary disease, depends, not on a spinal affection, but on a lesion of the nerves of the sacral plexus directly produced as it were, by gradual propogation of the morbid process" (Charcot, 1881).

"Other nervous symptoms of uremia are intense itching of the skin, numbness and tingling of the fingers, and cramps in the muscles of the calves, particularly at night" (Osler, 1892).

\section{INTRODUCTION}

Charcot and Osler clearly suspected the existence of uremic neuropathy, but at that time metabolic disturbances and coma dominated the clinical picture of terminal renal failure and neuropathy was easily overlooked. Not until 1963 (Asbury et al.) were the detailed clinical and pathological features fully described. This report will summarize my observations since 1966 and relate them to the pertinent literature, emphasizing the different varieties of peripheral nerve disorder, neurophysiological tests, and the effects of various treatments on the course of uremic polyneuropathy.

\section{TYPES OF NEUROPATHY}

Primary disease neuropathy (Table 1; Bolton et al., 1979 a), due to the same disease originally effecting the kidney - diabetes mellitus, vasculitis, amyloidosis or multiple myeloma usually has distinctive features. For example, cranial nerve palsies, compressive neuropathies, and autonomic involvement are prominent features of diabetic, but not uremic, polyneuropathy. 


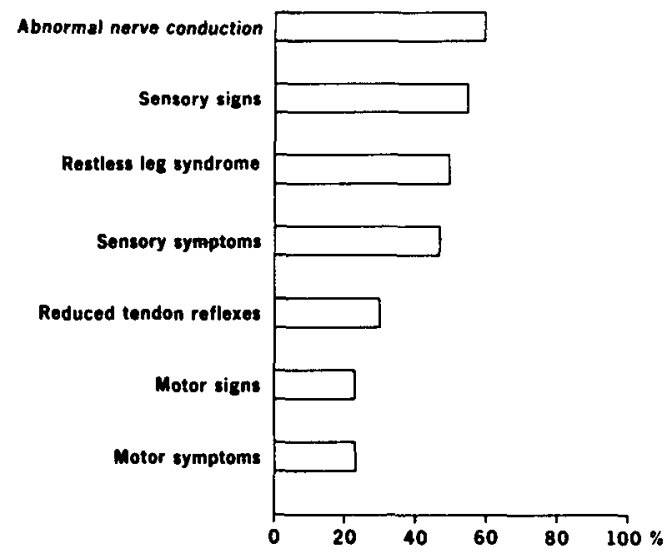

Figure 1 - Incidence of signs and symptoms in 30 unselected patients on chronic hemodialysis at Victoria Hospital, London, Ontario, 1973.

Uremic polyneuropathy may occur at any age, once the degree of renal failure is sufficient. It is, inexplicably, commoner in males than females (Asbury, 1975). The prevalence of signs and symptoms, and the order of their appearance have a similar pattern (Figure 1), one that is common to many distal, motor and sensory polyneuropathies. The variable progress (Figure 2 ) is only partly explained by types of dialysis procedure, intercurrent illness, and effects of renal transplantation. Rarely, the condition becomes crippling, with all limbs weak and wasted, deep tendon reflexes absent, and all sensation lost in a stocking-glove pattern.

Of the associated neuropathic syndromes, the burning foot syndrome was initially common. It resulted from the water soluble vitamin $B_{1}$ being removed during hemodialysis, but with replacement this syndrome is now rare. The restless leg syndrome and muscle cramps are common, but both may not be due to neuropathy (Nielsen, 1971). Autonomic neuropathy undoubtedly occurs, as shown in physiological studies by Kersh et al. (1974), and by the involvement of nonmyelinated fibers (Dyck et al., 1971). However, it is usually clinically insignificant. In unselected patients (Figure 1), sweating in fingers and toes tested by the ninhydrin method and postural changes in blood pressure were normal.

A Guillain-Barre type of neuropa-

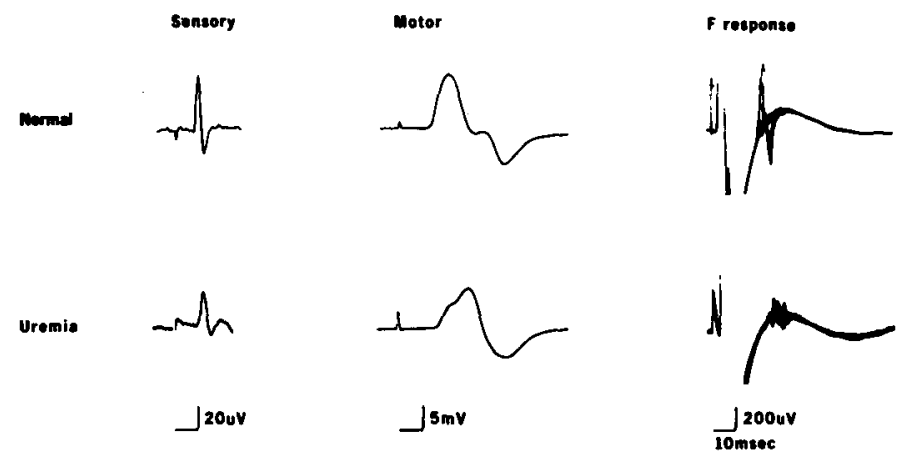

Figure 3 - Comparison of median nerve conduction results in a healthy person and a patient with mild uremic neuropathy, both females of similar age and height. All results are from supramaximal stimuli at the wrist. Note prolonged latencies and reduced and dispersed action potentials on antidromic sensory, and orthodromic motor conduction in uremia. The $F$ response latency, representing time of antidromic motor conduction to anterior horn cells and then orthodromic conduction down motor axons to thenar muscle, in a measure of both proximal and distal conduction times.

thy termed "monophasic motor neuropathy" (Bolton et al., 1979 a) is also rare. It may be uremic polyneuropathy with prominent motor manifestations and acute onset, or an autoimmune neuropathy predisposed to by immunodeficiency associated with renal failure. The differentiation is difficult because the CSF protein is elevated in most patients with uremic neuropathy (Jennekins et al., 1971), simulating the "albumino-cytologic" dissociation of Guillain-Barre syndrome.

Compression of the ulnar nerve at the elbow, or the peroneal nerve at the fibular head, occasionally occurs in cachectic patients recumbent for long periods. The carpal tunnel syndrome may occur distal to forearm arteriovenous fistulas used for access during hemodialysis, presumably because of distal ischemia or edema (Harding and Le Fanu, 1977). Excessive arteriovenous shunting from a bovine shunt located in the upper arm may cause permanent ischemic neuropathy (Bolton et al., 1979 b). The bleeding tendency associated with uremia or with anticoagulant therapy may cause psoas muscle hematoma with femoral nerve compression, requiring surgical decompression.

Nitrofurantoin, less commonly pen- cillin $\mathrm{G}$, causes a polyneuropathy with clinical features similar to uremic polyneuropathy but electrophysiological and pathological features suggest a purely axonal degeneration. Kanamycin, Gentamycin, etc., cause a similar neuropathy or a defect in neuromuscular transmission.

\section{NEUROPHYSIOLOGICAL TESTS}

Nielsen (1972) found nerve conduction velocities to be a sensitive test for uremic neuropathy. Reduced velocities often precede either symptoms or signs (Table 2; Figure 1). They reflect the clinical course of uremic neuropathy (Figure 2), the degree of paranodal and segmental demyelination, and segmental remyelination (Bolton et al., 1979 c) and, perhaps, the adequacy of hemodialysis (Jebsen et al., 1967). Excessive variation in serial tests of the same patient (Kominami et al., 1971) can be reduced by attention to technical detail.

Prolonged distal latencies (Figure 3) are due to involvement of distal nerve segments; dispersed compound action potentials are due to paranodal and segmental demyelination; and reduced compound action potential amplitudes are due mainly to reduced density of large myelinated motor 


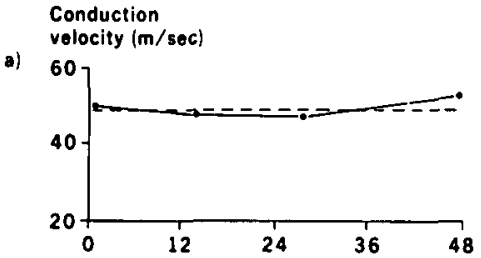

b)

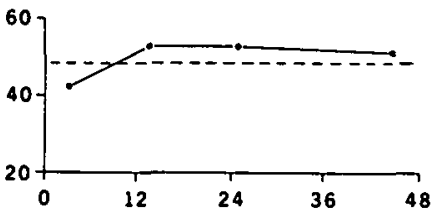

c)

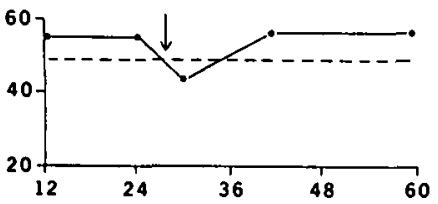

d)

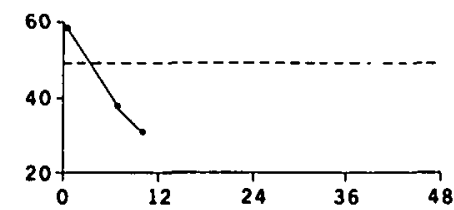

e)
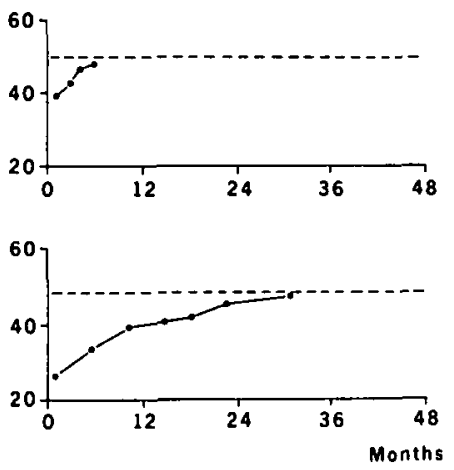

Figure 2 - Variations in the course of uremic neuropathy in individual patients as reflected in median motor conduction velocity (---- 2 standard deviations below mean control value). Other nerves tested showed similar results.

a. A stable course in a 54 year old man on three times weekly home dialysis.

b. Improvement in uremic neuropathy in a 55 year old man on three times weekly home dialysis.

c. Transient worsening in uremic neuropathy in a 48 year old woman during intercurrent illness (!) - hysterectomy, septicemia and uremic encephalopathy.

d. Rapidly progressing neuropathy in a 21 year old man on twice weekly hemodialysis with a Kolff twin-coil unit. e. Rapid recovery after successful renal transplantation in a 43 year old man with only a subclinical neuropathy.

f. Gradual recovery after successful renal transplantation in a 21 year old man with severe, quadriplegic neuropathy.

(Bolton et al., 1979 c) and sensory (Buchtal et al., 1975) fibers. F response latencies are a measure of conduction time in both the proximal and distal segments of lower motor neurones, show less technical variation in serial tests, are considerably prolonged, and may prove particularly valuable in assessing uremic neuropathy (Panayiotopoulos et al., 1977). Needle electromyography reveals predominantly distal muscle denervation (Bolton et al., 1971), but only in more advanced neuropathy.

The electrophysiological estimate of the number of motor units in a muscle (Milner-Brown and Brown, 1976; McComas et al., 1971) correlates positively with the density of large, myelinated fibers (Bolton et al., 1979 c). Twenty patients on chronic hemodialysis (Bolton et Kaibara, 1975) had one third the normal number of units in the extensor digitorum brevis muscle, elevated excitation thresholds (Figure 4), and only a slight increase in a single unit voltage, suggesting a failure of collateral reinervation. Using computer methods, Hansen and Ballantyne (1978) showed similar results. A predominantly demyelinating lesion could account for the absence of collateral reinnervation, also suggested by single fiber EMG studies (Thiele and Stalberg, 1975). The refractory periods are normal in motor fibers (Delbeke et al., 1978), but are decreased in sensory fibers (Lowitzsch et al., 1979).

Six of 20 patients had abnormal touch pressure sensation tested quantitively and 10 of 17 had nerve conduction abnormalities, both methods correlating well with morphological abnormalities on nerve biopsy (Dyck et al., 1975). Vibratory perception thresholds, measured quantitavely, are specific but were relatively insensitive in detecting uremic neuropathy (Nielsen, 1972, 1974).

\section{INCIDENCE AND COURSE}

During conservative management prior to hemodialysis, conduction velocity falls and by "end stage" renal failure (creatine clearance $<10 \mathrm{ml}$./ min.) $50 \%$ of patients will have reduced velocities (Figure 5; Nielsen, 1973). However, such patients have only mild or subclinical neuropathy, particularly now with earlier institution of chronic hemodialysis (Figure 6).

Jebsen et al. (1967) found nerve conduction was unaffected by a single hemodialysis procedure. But Stanley et al. (1977) showed a rise in the amplitude of muscle and sensory nerve compound action potentials, even though conduction times and nerve excitation thresholds were unaffected; they proposed that either the number of conducting nerve fibers or the action potential amplitude of individual nerve fibers was increased.

Early experience with chronic hemodialysis suggested that the degree of

TABLE ।

The Neuropathies of Renal Failure

1) PRIMARY DISEASE NEUROPATHY

Diabetic

Arteritic

Amyloid

Multiple Myeloma

2) UREMIC POLYNEUROPATHY

Subclinical

Clinical

3) ASSOCIATED NEUROPATHIC SYNDROMES

Burning Foot

Restless Leg

Autonomic Neuropathy

Monophasic Motor Neuropathy

4) MONONEUROPATHY

Ulnar

Peroneal

Femoral

Associated With Arteriovenous Fistulae

5) DRUG INDUCED NEUROPATHY

Nitrofurantoin

Penicillin

Kanamycin

Gentamycin, Etc. 
TABLE II

Incidence and Course of Uremic Neuropathy, Determined by Clinical and Electrophysiological Methods, in Hospital and Home Dialysis Patients

\begin{tabular}{l|ccccc|ccc}
\hline & Subclinical & Mild & $\begin{array}{c}\text { Incidence } \\
\text { Moderate }\end{array}$ & Severe & Total & Improved & Same & Worse \\
\hline $\begin{array}{c}\text { Hospital } \\
(\mathrm{n}=18)\end{array}$ & $4(22)^{*}$ & $6(33)$ & 0 & 0 & $10(55)$ & 0 & $16(89)$ & $2(11)$ \\
$\begin{array}{c}\text { Home } \\
(\mathrm{n}=12)\end{array}$ & $5(42)$ & $2(17)$ & 0 & 0 & $7(59)$ & 0 & $10(83)$ & $2(17)$ \\
\hline
\end{tabular}

$$
\text { - (\%) }
$$

uremic neuropathy, particularly as monitored by nerve conduction studies, reflected the "adequacy" of dialysis. The incidence was less with parallel plate (Kiil) dialyzers than coil (Kolff) dialyzers (Tyler, 1968), and increasing either the frequency or total duration per week of hemodialysis caused improvement (Tenckhoff et al., 1967). Babb et al. (1971) proposed "middle molecules" were toxic to peripheral nerve and their satisfactory clearance could be estimated by calculating the number of hours of dialysis per week $x$ the surface area of the dialyzer $\div$ the body weight (Figure 7).

My observations have not entirely supported these ideas. In Saskatoon, Saskatchewan, between 1967 and 1970 , I found $70 \%$ of 30 patients on chronic hemodialysis had uremic neuropathy, in $30 \%$ it was moderate or severe. Subsequently, none improved and several deteriorated (Figure $2 \mathrm{~d}$ ), despite increase in dialysis frequency from 2 times to 3 times weekly. This incidence was similar to patients being dialyzed with the Kiil machine in
London England (Konotey-Ahulu et al., 1965), but differed in the failure to improve. In London, Ontario, between 1973 and 1975 , the total incidence in 30 patients was only $57 \%$, and moderate and severe neuropathies were initially absent (Table 2; Bolton et al., 1976). The use of a more modern $1 \mathrm{~m}^{2}$ Gambro-Lundia dialyzer with a $17 \mu$ cuprophan membrane is only one explanation of the differing incidence between the two centers. Earlier institution of chronic hemodialysis in the course of conservative manage-

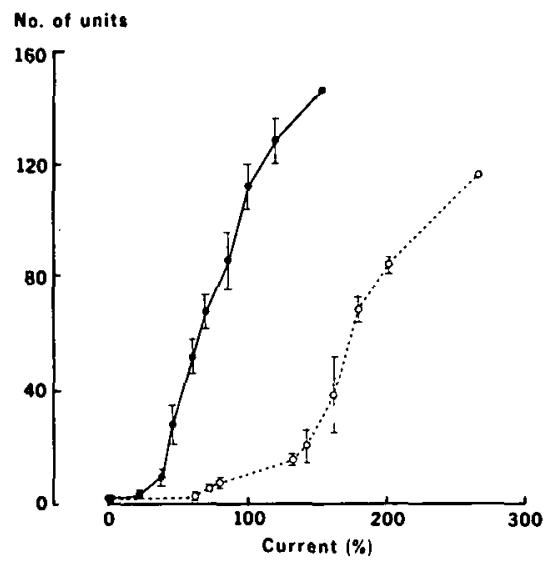

Figure 4-Increased excitation thresholds of motor axons in a 46 year old male $\left({ }^{\circ}-_{-}^{\circ}\right)$ on three times weekly home dialysis for one year, compared to a healthy male of similar age and build $(\bullet-)$. Groups of motor units (mean and range, ordinate) of similar threshold in the extensor digitorum brevis muscle were evoked by increasingly strong electrical stimuli to the common peroneal nerve at the knee. The number of motor units was calculated by Method II of Milner-Brown and Brown (1976). Each increase in current strength ( $\mathrm{mA}$, abscissa) was expressed as the percentage of current required to excite the first unit. There was no other clinical or electrophysiological sign of neuropathy in this patient, suggesting elevated excitation thresholds may be a very early sign of uremic neuropathy (Wright and McQuillen, 1973).

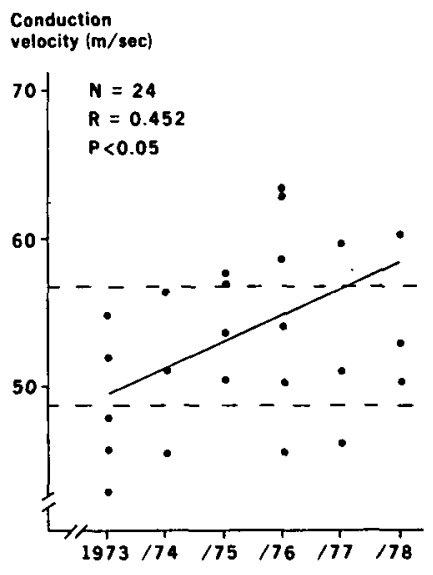

Figure 6 - The relationship of median motor conduction velocity (-- mean and -2 standard deviations of control values) to the year chronic hemodialysis was first instituted in each patient, in London, Ontario. The positive linear correlation suggests chronic hemodialysis was begun earlier in the course of chronic renal failure in recent years, before uremic neuropathy had become established. 
Conduction

velocity $(\mathrm{m} / \mathrm{sec})$

в)

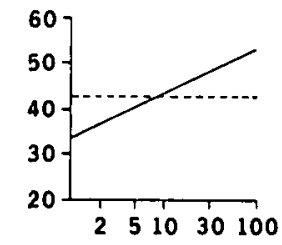

Creatinine clearance $(\mathrm{ml} / \mathrm{min}$.)

b)

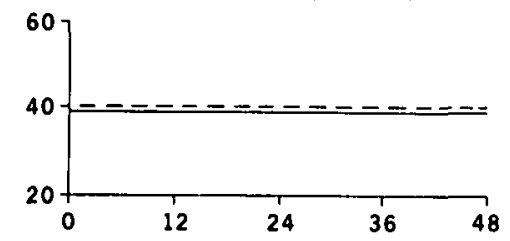

Months of $2 \times$ weekly hospital dialysis

c)

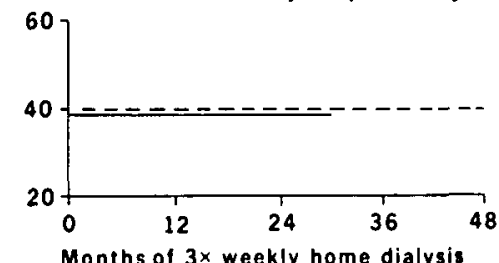

d)

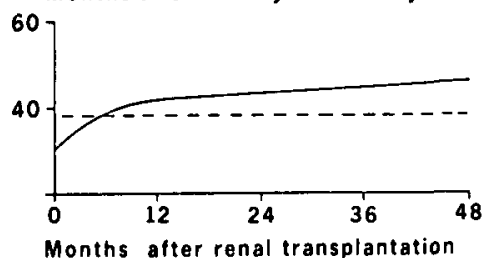

Figure 5 - Variations in the course of neuropathy in groups of patients as reflected in peroneal motor conduction velocity. During conservative management before hemodialysis (a) the conduction velocity progressively falls as renal function fails. Conduction velocity stabilizes at the lower limits of normal (--) to a similar degree for twice weekly (b) and thrice weekly (c) hemodialysis. Successful renal transplantation (d) causes a progressive rise in conduction velocity, the more rapid rise occurring initially. (Regression analysis in graphs are based on data from (a) 56 patients from Nielsen's (1973f) studies, $\mathrm{N}=56, \mathrm{r}=+0.68, \mathrm{p}<0.001$; (b) and (c) 10 patients each from studies by Bolton (unpublished) (b) $\mathrm{N}=22, \mathrm{r}=+0.00, \mathrm{p}>$ 0.05 ; (c) $\mathrm{N}=22, \mathrm{r}=-0.01, \mathrm{p}>0.05$; and (d) 10 patients from studies by Bolton (1976, $\mathrm{N}=24$, power curve, $\mathrm{p}<0.001$.

ment (Figure 6), greater residual renal function, de-ionisation or reverse osmosis of water for dialysis, less infection using arteriovenous fistulas instead of shunts, and earlier transplantation in uncontrolled uremic toxicity are other explanations.
To more thoroughly investigate the relationship between chronic hemodialysis methods and uremic neuropathy, 30 patients in London, Ontario, underwent a series of investigations. The neuropathy was assessed by serial, clinical, and nerve conduction studies. Eighteen were dialyzed 2 times weekly on a hospital program and 12, 3 times weekly on a home program. The two groups had the same incidence and course (Table 2), even though patients on the home program had a better feeling of well-being, less anemia, and improved platelet function. The neuropathy in both groups stabilized but did not improve and two patients in each regressed, one on the home program becoming quadriplegic. Since the two groups were not strictly comparable, ten were selected from each who were similar in age, initial severity of neuropathy, and total duration of chronic hemodialysis but no significant differences in neuropathy were demonstrated (Figure $5 \mathrm{~b}, \mathrm{c}$ ). Then, the home and

\section{Conduction velocity $(\mathrm{m} / \mathrm{sec})$}

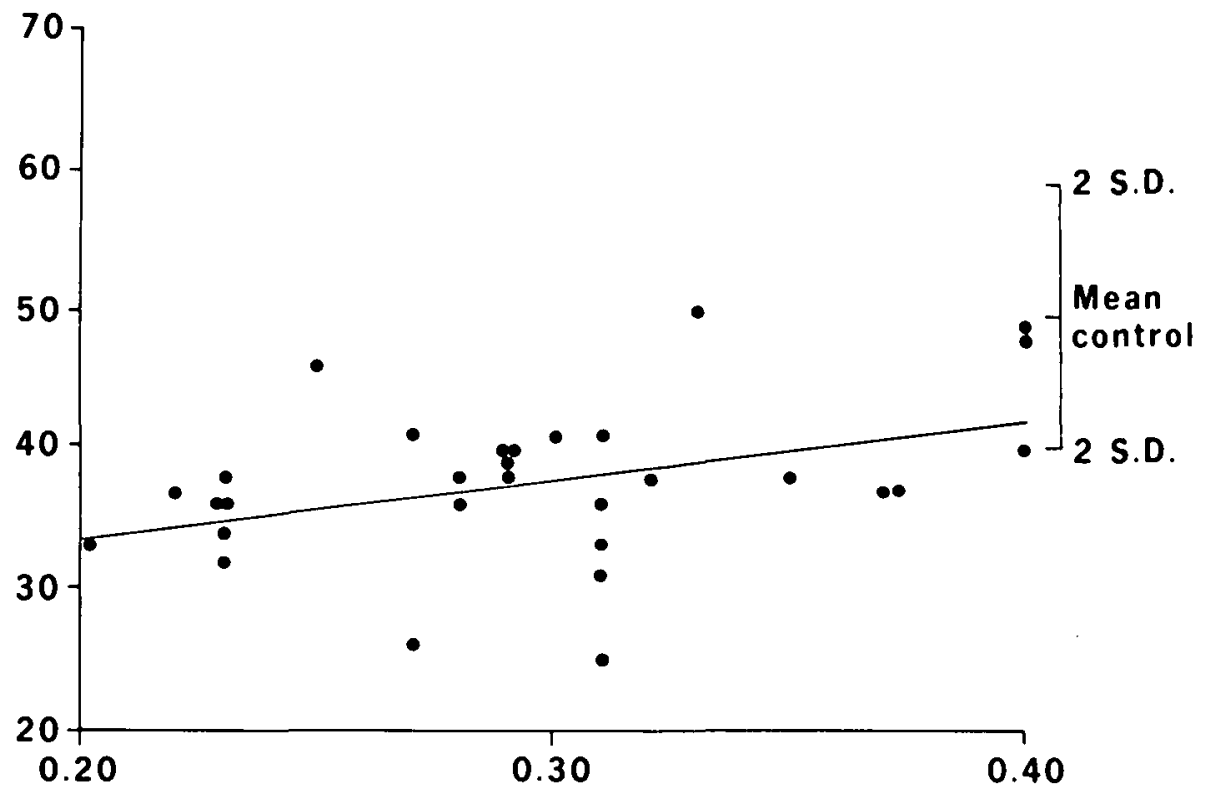

SQ. M.H./KG. B.W.

Figure 7 - The relationship of the final peroneal motor conduction velocity determination to the square meter hours per $\mathrm{Kg}$. body weight (Sq. M.H./ Kg. B.W.) of hemodialysis in each of 30 patients on chronic hemodialysis for 30 (10-79) months. While suggesting a positive linear correlation, and presumably better clearance of "middle-molecules" with increased conduction velocity, the result was not statistically significant $(N=30, r=$ $+0.412, \mathrm{p}>0.05$ ). hospital groupings were discarded and the middle molecule clearance (see above: Babb et al., 1971) and final conduction velocity were compared in each of the 30 patients (Figure 7). While the resulting positive linear regression line was statistically insignificant, it suggests a trend requiring further investigation. Finally, using the patient as his own control, six, whose neuropathy was stable for two years, were switched from 2 times to 3 times weekly hemodialysis; nerve conduction studies every four months for one year on this group and six healthy controls were unchanged for conduction velocity, $F$ response latency, or muscle and sensory compound action potential amplitude.

Thus, modern methods of managing renal failure have clearly decreased the incidence of uremic neuropathy and chronic hemodialysis stabilizes this condition in most patients, improving However, the course of the neuropathy or worsening it in a few (Figure 2). 
cannot be improved with certainty by manipulating the hemodialysis schedule, at least within the limits of current practice. Nor are standard nerve conduction studies a reliable method of determining the adequacy of hemodialysis, other systemic evidence of uremic toxicity appearing earlier, as shown in our studies and in a recent study by Dyck et al. (1979).

Blair (1977) has compared patients, on peritoneal hemodialysis to those on hemodialysis. The results for chronic hemodialysis were similar to our London patients, the neuropathy stabilizing at two standard deviations below mean control values. However, the neuropathy tended to worsen slowly during peritoneal dialysis. These results are notable since one might have expected the neuropathy to improve, the peritoneal membrane being more selective in passing various molecular weight substances, including "middle molecules", than the artificial membrane in hemodialysis machines (Asbury, 1975).

Initially, the degree of improvement in neuropathy after successful renal transplantation was questioned (Merrill and Hampers, 1970), particularly if the neuropathy was severe (Jebsen et al., 1967). However, remarkable improvement in symptoms, signs, and nerve conduction studies occurred in ten patients, three with severe neuropathy, after this procedure (Bolton et al., 1970, 1971). Subjective improvement began within one month, and although recovery was prolonged beyond two years in severe cases, none was left with a significant disability. A disabling action tremor in another patient, presumably secondary to severe neuropathy, eventually disappeared after full recovery (Casano, 1972).

Nerve conduction velocities show a rapid rise initially, particularly in milder neuropathies (Figure 2 e, f), levelling off later (Dobblestein et al., 1968). Paranodal remyelination by still viable Schwann cells likely explain the early rise and segmental remyelination by intercalation of new Schwann cells (Allt et al., 1969; Allt, 1960) explains both the late rise and restitution of dispersed action potentials (Bolton et al., 1971; Bolton, 1976). Surprisingly, conduction velocities may rise within a few days of successful renal transplantation, Oh et al. (1978) speculating a metabolic cause.

If the transplanted kidney undergoes late failure, uremic neuropathy may develop a second time, but be reversed by a further successful renal transplant (Bolton, 1976). This fluctuation is related to the functional state of the transplanted kidney and not to prednisone and immunosuppressive drugs used routinely after surgery to prevent or to treat rejection (Bolton et al., 1971).

\section{PATHOPHYSIOLOGY AND ETIOLOGY}

The peripheral nerves show distal segmental demyelination and axonal degeneration, and the spinal cord, chromotolysis of anterior horn cells (Asbury and al., 1973). Severe demyelination of lumbosacral nerve roots may occur in advanced neuropathy (Bolton and Rozdilsky, 1971). Teased fiber studies reveal paranodal demyelination, segmental demyelination, axonal degeneration, and segmental remyelination (Figure 8). Quantitative studies show a reduction of large and small myelinated and unmyelinated fibers (Dyck et al., 1971). However, all pathological observations to date have been nonspecific (Asbury, 1975).

Mechanisms underlying the neuropathy are unknown. Teased fiber techniques (Dinn and Crane, and Dayan et al., 1970), light and electron microscopy, and biochemical dialysis by gas liquid chromotography of whole peripheral nerves (Appenzeller et al., 1971) suggested Schwann cell dysfunction was the primary event. However, Dyck et al. (197l) and Thomas et al. (1971) suggested segmental demyelination was secondary to a primary axonal degeneration. The ratio of the circumference of axis cylinders to the number of myelin lamellae was decreased in distal nerve fibers, suggesting axon shrinkage. Segmental demyelination tended to occur only on certain fibers, completely sparing others, suggesting that demyelination was secondary to axonal disease. Demyelination and axonal degeneration were much more severe distally.

However, in the early stage of uremic neuropathy, there is slowing of conduction in proximal and distal a)

c
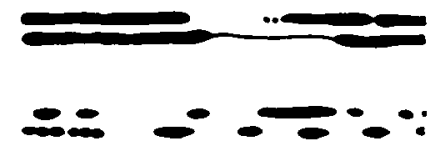

$F$

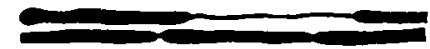

Superficial peroneal nerve

b)

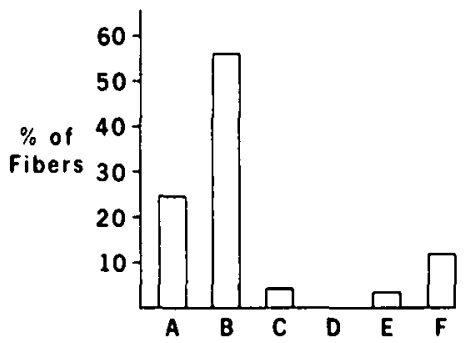

Deep peroneal nerve

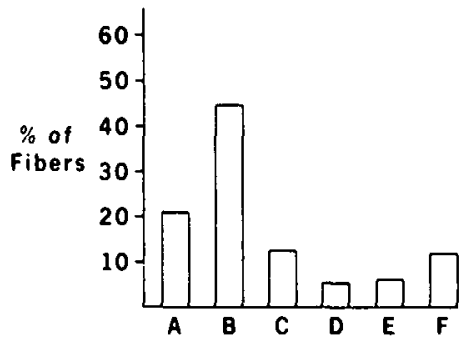

Figure $8-$ Teased fiber results in uremic neuropathy. Graph a) shows teased fiber classification (Dyck et al, 1971): A and $B$ are normal fibers, $C$ - paranodal demyelination, D - segmental demyelination, $\mathrm{E}$ - axonal degeneration, and $\mathrm{F}$ segmental remyelination. Graph b) shows teased fiber results for two nerves biopsied at the ankle in a sixty-five year old woman on twice weekly GambroLundia Nova dialyzer for 18 months, who had a mild, stable polyneuropathy.

portions of peripheral nerves (Nielsen, 1973) and an electrodecremental response typical of that seen when normal human nerves are rendered ischemic (Nielsen, 1974). Nielsen explained 
both by an inhibition of sodium potassium activated ATPase at the nerve axon membrane.

Perhaps membrane dysfunction is occurring at the perineurium which functions as a diffuse barrier between interstitial fluid and nerve, or in blood capillaries within the endoneurium, which act as barriers between blood and nerve. As a result, uremic toxins might enter the endoneural space at either site and not only cause direct nerve damage, but also water and electrolyte shifts with expansion or retraction of this space. Since the amplitude of sensory compound action potentials is positively related to the density of myelinated nerve fibers (Lambert and Dyck, 1975), such endoneural volume changes would affect this density and may explain alterations in these amplitudes observed in uremia: their failure to decrease during limb ischemia, enhanced by a single hemodialysis procedure and abolished by macromolecular perfusion (Castaigne et al., 1972); or their rise after a single hemodialysis procedure (Stanley et al., 1972).

The nature of the toxic substance, or substances, in uremia is also unknown. Deficiency of thiamine, magnesium, or erythrocyte transketolase (an enzyme in the pentose phosphate shunt, particularly concentrated in myelin-rich areas of the nervous system) is unproven (Asbury, 1975). An accumulation of toxins is more likely. Urea and creatinine, of low molecular weight, are effectively reduced by hemodialysis, but their concentrations bear a poor relationship to neuropathy. Myoinosital, molecular weight 180 , a precursor of phosphoinositide, is rapidly metabolized in neural membranes. It is abnormally elevated in chronic renal failure, poorly eliminated by hemodialysis, but, being normally excreted by renal cortex, is handled effectively by a successfully transplanted kidney. Thus, Clements et al., (1973), suggested it was the peripheral nerve toxin. They found reversible reduction in conduction velocities of experimental animals fed excessive amounts of myoinosital. However, Reznek et al. (1977) demonstrated no convincing relationship between human uremic neuropathy and plasma myoinosital levels.
The "middle molecule" theory is currently the most plausible (Babb et al., 1971). These substances, molecular weight 300 to 2,000 , are abnormally elevated in end-stage renal failure, and, while not greatly reduced by chronic hemodialysis, are more effectively reduced by parallel plate (Kiil) dialyzing units than coil (Kolff) dialyzers. When detected by in vitro chromotographic fractionation, they correlate with the degree of neurotoxicity, shown by a bioassay method (Funck-Brentano et al., 1978). The transplanted kidney deals effectively with substances of wide ranging molecular weights, the resulting elimination of middle molecules explaining the invariable improvement in neuropathy after transplant (Editorial, 1971).

\section{ACKNOWLEDGEMENTS}

I am grateful for the help and co-operation of Doctors Mark Baltzan and Richard Baltzan, nephrologists, Dr. Bodan Rozdilsky, neuropathologist, and Mrs. Donalda White, technician, Saskatoon, Saskatchewan. Canada: and Doctors Adam Linton and Robert Lindsay, nephrologists, Dr. Joseph Gilbert, neuropathologist, Mrs. M. Kaibara and K. Carter, technicians, and Miss Betsy Toth, secretary, London, Ontario, Canada.

\section{REFERENCES}

ALLT, G. (1969). Repair of segmental demyelination in peripheral nerves. An electron microscope study. Brain, 92, 639-646.

ALLT, G. and CAVANAGH, J. B. (1969). Ultrastructural changes in the region of the node of Ranvier in the rat caused by diphtheria toxin. Brain, 92, 459-468.

APPENZELLER, O., KORNFIELD, M., ALBUQUERQUE, N.M. and MacGEE, J. (1971). Neuropathy in chronic renal disease. Arch. Neurol., 24, 449.

ASBURY, A. K. (1963). Peripheral neuropathy due to nitrofurantoin. Lancet I, 334.

ASBURY, A. K. (1975). Uremic neuropathy. In Dyck, P.J., Thomas, P.K., Lambert, E. (eds): Peripheral Neuropathy. Philadelphia, Saunders, pp. 982-992.

ASBURY, A.K., VICTOR, M. and ADAMS, R. D. (1963). Uremic polyneuropathy. Arch. Neurol. (Chic.) 8, 413 .

BABB, A. L., POPOVICH, R.P., CHRISTOPHER, T.G. and SCRIBNER, B. H. (1971). The genesis of the square meter-hour hypothesis. Trans. Am. Soc. Artif. Intern. Organs, 17, 81 .

BALTZAN, M.A. and BALTZAN, R.B. (1971). Clinical value of cadaveric renal homotransplantation. Can. Med. Assoc. J., 104, 293-296.
BLAIR, G. B. (1977). Personal Communication. BOLTON, C.F. (1976). Electrophysiologic changes in uremic neuropathy after successful renal transplantation. Neurology, 26, 152-161.

BOLTON, C.F., BALTZMAN, M.A. and BALTZAN, R. B. (1970). Uremic neuropathy during hemodialysis and following renal transplantation. Ann. R. Coll. Physicians Surg. Can., 2, 37.

BOLTON, C.F., BALTZAN, M. A. and BALTZAN, R.B. (1971). Effects of renal transplantation on uremic neuropathy. New Engl. J. Med., 284, 1770-1775.

BOLTON, C. F. and ROZDILSKY, B. (1971). Electrophysiological and structural changes in uremic neuropathy. Presented at the 6th Canadian Congress of Neurological Sciences, St. Johns, Newfoundland, June 16-19.

BOLTON, C. F. and KAIBARA, M. (1975). Electrophysiological signs of peripheral neuropathy during chronic hemodialysis. International Congress of Electromyography, Rochester, Minn., U.S.A., September.

BOLTON, C.F., LINDSAY, R.M. and LINTON, A. L. (1976). Studies of uremic neuropathy in patients on home and hospital dialysis programs. In Regional Management of Terminal Renal Failure: Review and Eternal Audit. Edited by Lindsay, R. M. and Linton, A. L. University of Western Ontario Press.

BOLTON, C. F., LINDSAY, R.M. and LINTON, A. L. (1977). Uremic neuropathy in patients on different hemodialysis schedules. Neurology, 27, 396.

BOLTON, C. F., JOHNSON, W.J. and DYCK. P.J. (1979 a). Neurological manifestations of renal failure. In Strauss and Welt's Diseases of the Kidney. 3rd Edition. Edited by Earley, L. E. and Gottschalk, C. W. Little, Brown \& Co., Boston, Vol. 1, pp. 371-392.

BOLTON, C.F., DRIEDGER, A.A. and LINDSAY, R.M. (1979 b). Ischaemic neuropathy in uremic patients due to a bovine arteriovenous shunt. Journal of Neurol., Neurosurg., and Psych., 42, 810-814.

BOLTON, C.F., GILBERT, J.J., GIRVIN, J.P. and HAHN, A. $(1979 \mathrm{c})$. Nerve and muscle biopsy: Electrophysiology and morphology in polyneuropathy. Neurology, 29. 354-362.

BUCHTHAL, F., ROSENFALK, $A$. and BEHSE, F. (1975). Sensory potentials of normal and diseased nerves. In Peripheral Neuropathy. 1st Edition. Edited by Dyck, P.J., Thomas, P.K. and Lambert, E. H. W. B. Saunders Co., Toronto, Vol. I, pp. 442-464.

CASANO, A.A. (1972). Personal Communication.

CASTAIGNE, P., CATHALA, H.P., BEAUSSART-BOULENGE, L., and PETROVER, M. (1972). Effect of ischaemia on peripheral nerve function in patients with chronic renal failure undergoing dialysis treatment. Journal of Neurol., Neurosurg., Psychiat., 35, 631-637.

CHARCOT, J. M. (1880). Leçons sur les maladies du système nerveux. XVI des paraplé- 
gies urinaires. 3. Ed. (Ed. Bourneville), Paris, p. 295.

CLEMENTS, R.S., DEJESUS, P.V., and WINEGRAD, A.L. (1973). Raised plasma myoinositol levels in uremia and experimental neuropathy. Lancet, I, 1137-1141.

DAYAN, A.D., GARDNER-THORPE, C., DOWN, P. F. and GLEADLE, R. I. (1970). Peripheral neuropathy in uremia. Pathological studies on peripheral nerves from 6 patients. Neurology (Minneap.), 20, 649 .

DELBEKE, J., KOPEC, J. and McCOMAS, A. J. (1978). Effects of age, temperature, and disease on the refractoriness of human nerve and muscle. J. Neurol., Neurosurg., Psychiat., 41, 65-71.

DINN, J. J. and CRANE, D. L. (1970). Schwann cell dysfunction in uremia, J. Neurol,, Neurosurg., Psychiat., 33, 605.

DOBBELSTEIN, H., ALTMEYER, B., EDEL, H., GURLAND, H.J., MULLER, R., PICHLMAIER, $H$. and JABOUR, $A$. (1968). Periphere neuropathie bei chronischen niereninsuffizienz, bei dauerdialyse behandlung und nach nierentransplantation. Med. Klin., 63, 616

DYCK, P.J., JOHNSON, W.J., LAMBERT, E. H., and O'BRIEN, P.C. (1971). Segmental demyelination secondary to axonal degeneration in uremic neuropathy. Mayo Clin. Proc., 46, 400.

DYCK, P.J., JOHNSON, W.J., LAMBERT, E.H., BUSHEK, W. and POLLOCK, $M$. (1975). Detection and evaluation of uremic peripheral neuropathy in patients on hemodialysis. Kidney international, Vol. 7, S201205.

DYCK, P.J., JOHNSON, W.J., LAMBERT, E. H., O'BRIEN, P.C., DAUBE, J.R., and OVIATT, K.F. (1979). Comparison of symptoms, chemistry, and nerve function to assess adequacy of hemodialysis. Neurology, 29, 1361-1368.

EDITORIAL. (1971). Erythrocyte transketolase inhibition, neuropathy and uremia. $\mathrm{N}$. Engl. J. Med, 284, 1435-1436.

FUNCK-BRENTANO, J. L., CUEILLE, G.F., and MAN, N.K. (1978). A defense of the middle molecule hypothesis. Kidney International, Vol. 13. Suppl. 8, \$31-35.

HANSEN, S. and BALLANTYNE, J. P. (1978). A quantitative electrophysiological study of uremic neuropathy. Diabetic and renal neuropathies compared. J. Neurol., Neurosurg., Psychiat., 41, 128-134.
HARDING, A.E. and LE FANU, J. (1977). Carpal tunnel syndrome related to antebrachial Cimino-Brescia fistula. J. Neurol., Neurosurg., Psychiat., 40, 511-513.

JEBSEN, R.H., TENCKHOFF, H., and HONET, J.C. (1967). Natural history of uremic polyneuropathy and effects of dialysis. N. Engl. J. Med., 277, 327-333.

JENNEKINS, F. G. I. (1971). Clinical aspects of uremic polyneuropathy. Nephron, 8, 414 .

KERSH, E.S., KRONFIELD, S. J., UNGER, A., POPPER, R.W., CANTOR, S., and COHN, K. (1974). Autonomic insufficiency in uremia as a cause of hemodialysis-induced hypotension. New Engl. J. Med., 290, 650653.

KOMINAMI, N., TYLER, H.R., HAMPERS, C.L. and MERRILL, J.P. (1971), Variations in motor nerve conduction velocity in normal and uremic patients. Arch. Intern. Med., 128, 235-239.

KONOTEY-AHULU, F.I.D., BAILLOD, R., COMTY, C. M., HERON, J.R., SHALDON, S., and THOMAS, P.K. (1965). Effect of periodic dialysis on the peripheral neuropathy of end-stage renal failure. Brit. Med. J., 2, 212.

LAMBERT, E. H., DYCK, P.J. (1975). Compound action potentials of sural nerve in vitro in peripheral neuropathy. In Dyck, P.J., Thomas, P. K., Lambert, E. H. (Editors). Peripheral Neuropathy. W. B. Saunders Co., Philadelphia. Vol. 1, p. 241.

LOWITZSCH, U., GOHRING, U., HECKING, E., and KOHLER, H. (1979). Refractory period, sensory conduction velocity and vibration before and after haemodialysis. Acta Neurol. Scandinavica, Suppl. 73, 60, 133.

McCOMAS, A.J., FAWCETT, P.R.W., CAMPBELL, M.T., and SICA, R.E.P. (1971). Electrophysiological estimation of the number of motor units within a human muscle. J. Neurol., Neurosurg., Psychiat., 34, 121-131.

MERRILL, J. P., and HAMPERS, C. L. (1970). Uremia. N. Engl. J. Med., 282, 953.

MILNER-BROWN, H.S. and BROWN, W.F. (1976). New methods of estimating the number of motor units in a muscle. J. Neurol., Neurosurg., Psychiat., 39, 258-265.

NIELSEN, V.K. (1971). The peripheral nerve function in chronic renal failure. I. Clinical symptoms and signs. Acta Med. Scand., 190, 105-111.
NIELSEN, V.K. (1972). The peripheral nerve function in chronic renal failure. IV. An analysis of the vibratory perception threshold. Acta Med. Scand., 191, 287-296.

NIELSEN, V.K. (1973). The peripheral nerve function in chronic renal failure. VI. Sensory and motor conduction velocity. Acta Med. Scand., 190, 119-125.

NIELSEN, V.K. (1974). The peripheral nerve function in chronic renal failure. $X$. Decremental nerve conduction in uremia? Acta Med. Scand., 196, 83.

OH, S. J., CLEMENTS, R. S., LEE, Y. W., and DIETHELM, A.G. (1978). Rapid improvement in nerve conduction velocity following renal transplantation. Ann. Neurol., 4, 369373.

OSLER, W. (1892). The principles and practice of medicine. p. 684, 699. 7th Ed. Appleton, London.

PANAYIOTOPOULOS, C. F. and SPARPALEYOS, S. (1977). F wave studies on the deep peroneal nerve. Part 2. 1. Chronic renal failure. 2. Limb-girdle muscular dystrophy. J. Neurol. Sci., 31, 331-341.

REZNEK, R.H., SALWAY, J.G. and THOMAS, P.K. (1977). Plasma myoinositol concentrations in uraemic neuropathy. The Lancet, March 26, 675-676.

STANLEY, E., BROWN, J.C. and PRYOR, J.S. (1977), Altered peripheral nerve function resulting from haemodialysis. Journal of Neurol., Neurosurg., Psychiat., 40, 39-43.

TECKHOFF, H., JEBSEN, R.H. and HONET, J.C. (1967). The effect of long-term dialysis treatment on the course of uremic neuropathy. Trans. Am. Soc. Artif. Intern. Organs, 13, 58-61.

THIELE, B. and STALBERG, E. (1975). Single fibre EMG findings in polyneuropathies of different etiology. Journal of Neurol., Neurosurg., Psychiat., 38, 881-887.

THOMAS, P.K., HOLLINRAKE, K., LASCELLES, R.G., O'SULLIVAN, D.J., BAILLOD, R.A., MOORHEAD, J.F. and MacKENZIE, J.C. (197!). The polyneuropathy of chronic renal failure. Brain, 94, 761.

TYLER, H.R. (1968). Neurologic disorders in renal failure. Am. J. Med., 734-748.

WRIGHT, E.A. and McQUILLEN, M.P. (1973). Hypoexcitability of ulnar nerve in patients with normal motor nerve conduction velocities. Neurology, 23, 78-83. 